\title{
Homoharringtonine increases intestinal epithelial permeability by modulating specific claudin isoforms in Caco-2 cell monolayers
}

Akihiro Watari*, Maki Hashegawa, Kiyohito Yagi, Masuo Kondoh*

Laboratories of Bio-Functional Molecular Chemistry, Graduate School of Pharmaceutical Sciences, Osaka University, Suita, Osaka 565-0871, Japan.

* Corresponding author:

Akihiro Watari, PhD, Laboratory of Bio-Functional Molecular Chemistry, Graduate School of Pharmaceutical Sciences, Osaka University, Suita, Osaka 565-0871, Japan; Tel: +81-6-6879-8198; E-mail: akihiro@phs.osaka-u.ac.jp

Masuo Kondoh, PhD, Laboratory of Bio-Functional Molecular Chemistry, Graduate School of Pharmaceutical Sciences, Osaka University, Suita, Osaka 565-0871, Japan; Tel: +81-6-6879-8196; Fax: +81-6-6879-8199; E-mail: masuo@phs.osaka-u.ac.jp 


\begin{abstract}
Homoharringtonine (HHT), a natural alkaloid produced by various Cephalotaxus species, has antileukemic activity in acute and chronic myelogenous leukemia. However, HHT can also induce unanticipated effects in the gastrointestinal tract, such as diarrhea and nausea/vomiting, but the mechanism behind these adverse effects has not been clarified. In the present study, we show that HHT affects the epithelial permeability of intestinal Caco-2 cell monolayers. HHT reduced the transepithelial electrical resistance (TER) of Caco-2 cells in a dose- and time-dependent manner. The HHT effect was reversible and no cytotoxicity was observed at the concentrations used. HHT simultaneously increased the paracellular flux of the $4 \mathrm{kDa}$ and $40 \mathrm{kDa}$ FITC-dextrans associated with the TER reduction. Immunoblotting analysis revealed that HHT decreased the protein expression of TJ components such as claudin-3, -5 , and -7 . However, the transcription levels of these claudins were not repressed by HHT treatment. HHT also disturbed the cellular localization of claudin-1 and -4. These changes coincided with the reduced barrier function. Our findings suggest that HHT enhances the paracellular permeability of Caco- 2 cell monolayers by modulating the protein expression and localization of claudin isoforms; these actions might be responsible for the gastrointestinal effects of HHT.
\end{abstract}

\title{
Keywords:
}

Homoharringtonine, Claudin, Tight junction, Epithelial barrier, Paracellular permeability 


\section{Introduction}

Homoharringtonine (HHT) is a cephalotaxus alkaloid obtained from Cephalotaxus species and induces cytotoxicity in cancer cells by inhibiting protein synthesis and promoting apoptosis [1-3]. There have been several reports that HHT has antileukemic effects in patients with acute myeloid leukemia (AML) or chronic myeloid leukemia (CML), and clinical trials have been conducted in the United States [4]. Although the tyrosine kinase inhibitor (TKI) imatinib mesylate (Gleevec) improves the therapeutic outcomes of CML patients in the clinical arena, HHT has provided an effective treatment for TKI-resistant CML patients with Bcr-Abl mutations and has emerged as an agent for the second-line as a valuable option in CML treatment. Indeed, omacetaxine mepesuccinate, a semisynthetic form of HHT, has recently been proved by the Food and Drug Administration (FDA) of the United States for the treatment of CML patients resistant to TKIs [5]. The main adverse effects of HHT in animal studies were hematopoietic toxicities, as well as gastrointestinal and cardiac toxicities [6]. In clinical trials, gastrointestinal effects, including diarrhea and nausea/vomiting, were the most frequent non-hematologic toxicities during the induction phase [7]. However, the mechanism underlying the HHT-induced gastrointestinal adverse effects remains unclear.

Mycotoxins are a diverse group of secondary fungal metabolites, some of which have found use as beneficial pharmaceuticals (e.g., penicillin, cyclosporin A, and lovastatin) [8]; however, dietary exposure to mycotoxins can represent a toxicological health risk such as impairment of the intestinal tract, leading to the penetration of normally excluded luminal substances that may promote intestinal disorders [9]. Mycotoxins are potent inhibitors of protein synthesis and their biological effects are associated with this type of intestinal impairment. For example, deoxynivalenol, ochratoxin A, and patulin compromise the intestinal tract by disrupting the integrity of tight junctions (TJs), which 
normally function to maintain intercellular permeability barriers, and thereby increasing intestinal permeability [10-13].

TJs are located at the apical end of the basolateral membranes of epithelial cell-cell connections, where their function is to seal the intercellular space $[14,15]$. TJs include several transmembrane proteins such as claudins, occludin, and junctional adhesion molecules (JAMs), as well as cytoplasmic scaffolding proteins such as ZO-1, ZO-2, and ZO-3 [16-20]. Claudins, which are tetra-transmembrane proteins with a molecular mass of $23 \mathrm{kDa}$, are the main constituent of the TJ-barrier integrity. The claudin family contains more than 27 members. The combined expression pattern of these proteins determines the unique TJ permeability of the epithelial tissues of organs [21]. Therefore, defects in intestinal epithelial barrier function are frequently associated with the disruption of TJ-integrity, and mycotoxins are implicated in this disruption through their ability to disturb the expression and/or cellular localization of TJ components such as claudins, occludin, and ZO-1. Furthermore, several reports suggested a possible link between the inhibitory effects of mycotoxins on protein synthesis and the alteration of TJ components $[12,22,23]$. Thus, the inhibitory effects of HHT on protein synthesis might be responsible for the induction of toxicity in the gastrointestinal tract. However, whether HHT influences epithelial TJ-integrity is unknown. Therefore, the purpose of this study was to evaluate the effect of HHT on intestinal barrier function. To that end, we used human intestinal Caco-2 cells, which show many characteristics of intestinal epithelium and have been frequently used as a model for the functional and molecular analysis of intestinal epithelium. 


\section{Materials and methods}

\subsection{Reagents}

Rabbit anti-claudin-1 polyclonal antibody (pAb) (51-9000), mouse anti-claudin-2 monoclonal antibody (mAb) (32-5600), rabbit anti-claudin-3 pAb (34-1700), mouse anti-claudin-4 mAb (32-9400), mouse anti-claudin-7 mAb (37-4800), rabbit anti-ZO-1 pAb (40-2200), rabbit anti-ZO-2 pAb (71-1400), mouse anti-Occludin mAb (33-1500), and rabbit JAM-A pAb (36-1700) were purchased from Invitrogen (Carlsbad, CA, USA). Rabbit anti-claudin-5 pAb (ab53765), mouse anti-E-cadherin mAb (610181), and mouse anti- $\beta$-actin mAb (A1978) were purchased from Abcam (Cambridge, MA, USA), BD Transduction Laboratories (Franklin Lakes, NJ), and Sigma-Aldrich (St Louis, MO, USA), respectively. Goat anti-Rabbit IgG peroxidase-conjugated antibody and goat anti-mouse IgG peroxidase-conjugated antibody were purchased from Millipore (Bedford, MA, USA). Anti-mouse IgG fluorescein conjugate and Alexa fluor 488 goat anti-rabbit IgG were purchased from Rockland Immunochemicals (Gilbertsville, PA, USA) and Molecular Probes (Eugene, OR, USA), respectively. Homoharringtonine (HHT) was purchased from Wako Pure Chemical Industries (Osaka, Japan).

\subsection{Cell culture}

The human colorectal adenocarcinoma cell line, Caco-2 (HTB-37), was obtained from the American Type Culture Collection. Caco-2 cells were cultured in Eagle's minimal essential medium (Nissui, Japan) supplemented with $10 \%$ fetal bovine serum in $5 \% \mathrm{CO}_{2}$ at $37^{\circ} \mathrm{C}$. The passage number used for the experiments was between 20 and 35 .

\subsection{Transepithelial electrical resistance (TER) assay}

Caco- 2 cells were seeded in transwell chambers $(6.5 \mathrm{~mm}$ diameter, $0.4 \mu \mathrm{m}$ pore size; Corning, MA, USA) at a density of $6 \times 10^{4}$ cells/well, and cultured for 10-14 days. When 
the TER values reached a plateau, HHT was added to the apical and/or basolateral sides, and the TER values were monitored by using a Millicell-ERS epithelial volt-ohmmeter (Millipore Corporation, Billerica, MA, USA).

\subsection{Cytotoxicity assay}

Caco- 2 cells were seeded in transwell chambers and cultured for 10-14 days as described for the TER assay. After being treated with HHT at the apical and basolateral sides for 24 h, cytotoxicity was measured by using the LDH-Cytotoxic Test (Wako, Osaka, Japan), which measures lactate dehydrogenase (LDH) release from the Caco- 2 cells, according to the manufacturer's instructions. Treatment with $0.2 \%$ Tween-20 diluted in PBS was used as a $100 \%$ lysis control. Optical density was measured at $570 \mathrm{~nm}$ by using a TriStar LB 941 microplate reader (Berthold, Wildbad, Germany).

\subsection{Paracellular tracer flux assay}

Caco- 2 cells were seeded in transwell chambers and cultured for 10-14 days as described for the TER assay. After the chambers were equilibrated with P buffer (10 mM HEPES, $\mathrm{pH} 7.4,1 \mathrm{mM}$ sodium pyruvate, $10 \mathrm{mM}$ glucose, $3 \mathrm{mM} \mathrm{CaCl}_{2}$, and $\left.145 \mathrm{mM} \mathrm{NaCl}\right), \mathrm{P}$ buffer containing $100 \mu \mathrm{M}$ FITC-labeled dextran of molecular mass 4 or $40 \mathrm{kDa}$ was added to the upper chamber. After a 1-h incubation, samples were collected from the bottom chamber and were measured with a TriStar LB 941 microplate reader (Berthold).

\subsection{Immunoblotting analysis}

Caco- 2 cells were seeded in transwell chambers $(24 \mathrm{~mm}$ diameter, $0.4 \mu \mathrm{m}$ pore size; Corning) at a density of $7.5 \times 10^{5}$ cells/well, and cultured for 10-14 days. The cells were then lyzed with cell lysis buffer (10 mM Tris-HCl, $\mathrm{pH} 7.4,0.3 \%$ SDS $)$ containing

protease inhibitor cocktail (Sigma-Aldrich). The cell lysates were run on an 
SDS-polyacrylamide gel and electroblotted onto a polyvinylidene difluoride membrane. The membranes were incubated successively with antibodies against claudin-1, $-2,-3,-4$, $-5,-7$, occludin, JAM-A, ZO-1, ZO-2, E-cadherin, and $\beta$-actin, and then with a horseradish peroxidase-conjugated anti-rabbit or -mouse $\mathrm{IgG}$ antibody. The reactive bands were detected by using an enhanced chemiluminescence reagent (GE Healthcare), and the signals were visualized with ImageQuant LAS4010 (GE Healthcare).

\subsection{Quantitative reverse transcription PCR (qRT-PCR) analysis}

Claudin-1, $-2,-3,-4,-5$, and -7 mRNA levels in cells treated with vehicle or HHT (5 $\mu \mathrm{M})$ for $24 \mathrm{~h}$ were analyzed by qRT-PCR analysis. After treatment with HHT, cells were washed with PBS, and the total RNA was extracted with TRIzol reagent (Invitrogen). Total RNA $(2 \mu \mathrm{g})$ was reverse-transcribed with oligo(dT) primers and a cDNA synthesis kit (Roche, Mannheim, Germany) according to the manufacturer's instructions. The resulting cDNA was used for qRT-PCR analysis. qRT-PCR was performed with SYBR Premix Ex Taq II (Takara, Shiga, Japan) by using an Applied Biosystems StepOne Plus system (Applied Biosystems, Foster City, CA, USA). Relative quantification was performed against a standard curve, and the values were normalized against the input determined for the housekeeping gene Glyceraldehyde 3-phosphate dehydrogenase $(G A P D H)$ PCR primers were as follows: claudin-1, (forward)

5'-AGATGAGGATGGCTGTCATTGG-3' and (reverse)

5'-CATGCTGTGGCAACTAAAATAGC-3'; $\quad$ claudin-2, (forward)

5'-CTCCTGGGATTCATTCCTGTTG-3' and (reverse)

5'-TCAGGCACCAGTGGTGAGTAGA-3'; claudin-3, (forward)

5'-ATCGTGTGCTGCGCGTT-3' and (reverse) 5'-GGCCCTCCCAGATGTTCTG-3'; 
claudin-4, (forward) 5'-TTGTCACCTCGCAGACCATC-3' and (reverse) 5'-CAGCGAGTCGTACACCTTG-3'; claudin-5, (forward) 5'-CTGCTGGTTCGCCAACATT-3' and (reverse) 5'-TGCGACACGGGCACAG-3'; claudin-7 (forward) 5'-AGAGCACGGGGATGATGAG-3' and (reverse) 5'-CACCCATGGCTATACGGGC-3'; GAPDH, (forward) 5'-GGTGGTCTCCTCTGACTTCAACA-3' and (reverse) 5'-GTGGTCGTTGAGGGCAATG-3'.

\subsection{Immunofluorescence staining}

Caco-2 cells were seeded in transwell chambers $(12 \mathrm{~mm}$ diameter, $0.4 \mu \mathrm{m}$ pore size; Corning, MA, USA) at a density of $1.5 \times 10^{5}$ cells/well, and cultured for 10-14 days. After treatment with HHT $(5 \mu \mathrm{M})$ for $24 \mathrm{~h}$, the Caco- 2 cells were fixed with $4 \%$ Paraformaldehyde (PFA) for 15 min, and permeabilized with $0.1 \%$ Triton X-100 in PBS for $5 \mathrm{~min}$. The cells were then blocked in 1\% BSA in TBS buffer $(20 \mathrm{mM}$ Tris- $\mathrm{HCl}, \mathrm{pH}$ 7.4, $40 \mathrm{mM} \mathrm{NaCl}$ ) containing $0.05 \%$ Tween-20 (T-TBS) for $1 \mathrm{~h}$, followed by incubation with anti-claudin-1, -4, occludin, ZO-1, and E-cadherin antibodies in 1\% BSA in T-TBS for $1 \mathrm{~h}$. After incubation with secondary fluorescence antibodies for $1 \mathrm{~h}$, the immunofluorescence images were observed by using the immunofluorescence microscope FSX 100 (Olympus, Tokyo, Japan).

\subsection{Statistical analysis}

Data are presented as means \pm SEM. Statistical analysis was performed by Student's $t$-test. 


\section{Results}

3.1 Homoharringtonine treatment decreases the transepithelial electrical resistance of Caco-2 cell monolayers.

To investigate the effect of HHT on the barrier function of epithelial cell sheets, we added HTT, over a concentration range of $1-10 \mu \mathrm{M}$, to the apical and basolateral sides of human intestinal Caco-2 cells that were cultured on transwell inserts for 10-14 days. HHT treatment clearly decreased TER values in a time and dose-dependent manner (Fig. 1a). The TER values in the Caco-2 cell monolayers after treatment with HHT started to decrease after $12 \mathrm{~h}$ and continued to decrease gradually until $48 \mathrm{~h}$. To evaluate any difference due to the route of HHT exposure, HHT was added to either the apical or the basolateral compartment, or to both compartments, of the transwell chamber. Basolateral administration of HHT resulted in a decrease of TER to $20 \%$ of the level in vehicle-treated (control) cells (Fig. 1b). The reduction of TER after dual exposure of HHT was comparable to that after only basolateral exposure.

The cytotoxicity of HHT was assessed by using the LDH release assay. The result showed that HHT was not cytotoxic to Caco-2 cells over the concentration range of 1-10 $\mu \mathrm{M}$ (Fig. 1c). Furthermore, the TER values recovered to control levels within $24-48 \mathrm{~h}$ of HHT removal when the cells were treated with HHT concentrations of up to $5 \mu \mathrm{M}$ (Fig. 1d), indicating that the changes in TER induced by HHT were not due to cell death and were reversible.

\subsection{Homoharringtonine treatment increases the paracellular permeability of Caco-2 cell} monolayers.

The effect of HHT on paracellular permeability was examined by using FITC-dextran as a paracellular tracer. The amount of FITC-dextran that passed across the Caco-2 cell monolayers was measured. Caco-2 cells were treated with HHT $(1-10 \mu \mathrm{M})$, and then 4 
$\mathrm{kDa}$ FITC-dextran was added to the apical compartment. After $1 \mathrm{~h}$, the fluorescence intensity was measured in the basolateral compartment. The results showed a dose-dependent increase in the paracellular flux of 4 kDa FITC-dextran (Fig. 2a), a finding that was consistent with the TER reduction induced by HHT treatment (Fig. 1a). Furthermore, $40 \mathrm{kDa}$ FITC-dextran also passed through the cell monolayers after HHT $(1-10 \mu \mathrm{M})$ treatment (Fig. 2b). Taken together with the results of the TER analysis, these data indicate that HHT clearly elevates the paracellular permeability of Caco- 2 cell monolayers.

\subsection{Homoharringtonine selectively affects the protein level and distribution pattern of} claudin isoforms in Caco-2 cells.

To investigate the mechanism by which HHT treatment enhances the paracellular permeability of Caco- 2 cell monolayers, we examined the protein expression of cell-cell adhesion molecules. Immunoblotting analysis revealed that HHT treatment significantly decreased the proteins level of claudin-3, -5, and -7 (Fig. 3a). In contrast, the transcription levels of claudin-3, -5 and -7 were not suppressed (Fig. 3b). Next, we assessed the effect of HHT on the cellular localization of the claudin-1, -4, occludin, ZO-1, and E-cadherin proteins by using immunofluorescence staining. Occludin, ZO-1, and E-cadherin localization was unaffected by HHT treatment. In contrast, HHT treatment dramatically affected claudin-1 and -4 distribution; the signals from these proteins were strongly detected in the intracellular compartment rather than at the cell membrane (Fig. 4). To examine the association between the altered protein level or the displacement of the claudin isoforms and the reduction in intestinal barrier function, we assessed the expression levels and cellular localization of the claudin isoforms over a time course after HHT treatment and replacement with fresh medium. The expression levels of claudin-3, -5 , and -7 started to decrease after $12 \mathrm{~h}$ and gradually decreased further until $24 \mathrm{~h}$ (Fig. 5a 
and b). These reduced levels were restored within $48 \mathrm{~h}$ of replacing the HHT-containing medium with fresh medium (Fig. 5c and d). The altered localization of claudin-1 and -4 that was observed after $12 \mathrm{~h}$ of HHT treatment was also reversed after HHT withdrawal (Fig. 5e). These data suggest that the HHT-induced changes to the claudin isoforms are correlated with the enhancement of the paracellular permeability of Caco-2 cell monolayers. 


\section{Discussion}

In this study, we hypothesized that the protein synthesis inhibitor HHT would affect epithelial barrier function, similar to the effects of mycotoxins in intestinal tissues and, therefore, we investigated the effect of HHT on intestinal barrier function. HHT induced a concentration- and time-dependent reduction in TER values in Caco-2 cell monolayers. Exposure of the cells to HHT via different routes showed that basolateral exposure induced a markedly decrease in TER compared with that after apical exposure. These results are consistent with a recent study of deoxynivalenol in which the barrier function of Caco-2 cell sheets was more susceptible to deoxynivalenol administration from the basolateral side compared with that from the apical side [13]. From these previous results, we assumed that the effect of HHT would be similar to that of mycotoxins due to their similar adsorption routes, which differ from that of the permeability enhancer melittin, which is reported to have a specific receptor on the apical surface [24]. The TER reduction was consistent with the enhanced paracellular flux of the FITC-dextrans, indicating that HHT enhanced epithelial permeability across Caco-2 cell monolayers. However, the permeability of $40-\mathrm{kDa}$ FITC-dextran was more restricted than that of 4-kDa FITC-dextran, indicating that HHT enhancement of TJ permeability is limited by molecular size.

HHT has potent antileukemic properties in various leukemia cell types [25, 26]. HHT induces the upregulation of the pro-apoptotic Bax and the downregulation of the protein inhibitor survivin $[27,28]$, leading to the induction of apoptosis in myeloid leukemia. Furthermore, HHT acts as a broad-spectrum tyrosine kinase inhibitor that inhibits the phosphorylation of signaling molecules activated by the oncogenic kinase proteins such as JAK2V617F and Bcr-Abl, which then blocks proliferative and survival signals in AML cell lines [29]. Although the primary effect of HHT on leukemia cells is induction of apoptosis, the HHT-induced barrier reduction in Caco-2 cell sheets occurred without 
cytotoxicity at concentrations of $0.1-10 \mu \mathrm{M}$, and was completely reversible after removal of the compound at up to $5 \mu \mathrm{M}$. Therefore, HHT cytotoxicity did not contribute to the HHT-enhanced paracellular permeability.

In intestinal epithelial tissues, various claudins are expressed including claudin-1, -2 , $-3,-4,-5,-7$, and -8 [30-32], where they contribute to barrier integrity [33, 34]. Other TJ components, such as OCLN, JAM-A, ZO-1, and ZO-2, and E-cadherin, are also associated with the barrier function in epithelial cells [35-41]. In our experiments, HHT-exposed Caco-2 cells exhibited reduced protein levels of claudin-3, -5, and -7, and internalization of claudin-1 and -4. In contrast, the expression and/or localization of the other TJ components and E-cadherin after HHT treatment did not significantly change, indicating that the intercellular junctions are not markedly impaired. The HHT-induced changes in the claudin isoforms and the barrier reduction occurred concomitantly, suggesting that the effect of HHT on the claudin isoforms led to the enhancement of paracellular permeability.

Previous studies have shown that HHT inhibits protein synthesis by hindering the peptidyl transferase activity of the ribosome and preventing translation elongation [3]. Similar activity has been observed with mycotoxins such as deoxynivalenol and ochratoxin A, and these toxins decrease the barrier integrity of Caco-2 cells $[10,11]$. Deoxynivalenol has been reported to induce TER reduction and increase the paracellular permeability of Caco-2 cell monolayers without impairing cell viability $[10,13]$. Furthermore, deoxynivalenol exposure has been shown to cause a reduction in protein synthesis in differentiated Caco-2 cells; this reduction may be linked to diminished claudin-4 protein expression, but not to claudin-4 transcription [22]. In our study, claudin-3, -5, and -7 protein expression was decreased by HHT treatment, but the transcription levels were not suppressed, suggesting that HHT might reduce claudin-3, -5 , and -7 protein levels by inhibiting protein synthesis. However, claudins may not be 
specific targets of the inhibitory effect on protein synthesis induced by HHT in intestinal cells. It has been reported that HHT rapidly reduces a number of short-lived proteins from various cell lines derived from hematological malignancies. Indeed, the neosynthesis of anti-apoptotic myeloid cell leukemia-1 (Mcl-1) and c-myc, which are short-lived proteins that regulate the proliferation and survival of leukemic cells, were inhibited in lymphoma cells in response to HHT treatment $[42,43]$. There may be other targets of HHT-induced inhibition of protein synthesis that are involved in the TJ-opening. Future studies should address which protein inhibitory effect(s) of HHT influence intestinal barrier function.

The present study demonstrated that HHT has the ability to reversibly open TJs via a mechanism that appears to involve the modulation of several claudin isoforms, and that these effects of HHT may be associated with the induction of gastrointestinal adverse events. Several reports have suggested that modulation of the TJ-barrier could be a potent strategy for the transport of various poorly absorbed drugs via the paracellular route [44]. Therefore, it was hypothesized that optimization of the HHT concentration or administration site could lead to the development of a permeability enhancer for the uptake of drugs through the epithelial barrier without causing adverse effects. However, little is known about the precise mechanism by which HHT exerts its effects on TJ components. Further study of the effects of HHT at the TJ-barrier may improve our understanding of epithelial barrier function controlled by TJ components as well as our knowledge of the control of TJ permeability in epithelial tissues. 


\section{Acknowledgements}

This work was supported by a Health and Labour Sciences Research Grant from the Ministry of Health, Labour and Welfare of Japan; a Grant-in-Aid for Scientific Research from the Ministry of Education, Culture, Sports, Science and Technology of Japan (26860078 to AW, 24390042 to MK); a grant from the Adaptable and Seamless Technology Transfer Program through Target-driven R\&D, Japan Science and Technology Agency; a grant from the Platform for Drug Discovery, Informatics, and Structural Life Science of the Ministry of Education, Culture, Sports, Science, and Technology, Japan; and the Takeda Science Foundation. 


\section{References}

[1] J.L. Grem, B.D. Cheson, S.A. King, B. Leyland-Jones, M. Suffness, Cephalotaxine esters: antileukemic advance or therapeutic failure?, J Natl Cancer Inst, 80 (1988) 1095-1103.

[2] C.C. Huang, C.S. Han, X.F. Yue, C.M. Shen, S.W. Wang, F.G. Wu, B. Xu, Cytotoxicity and sister chromatid exchanges induced in vitro by six anticancer drugs developed in the People's Republic of China, J Natl Cancer Inst, 71 (1983) 841-847.

[3] R.M. Tujebajeva, D.M. Graifer, G.G. Karpova, N.A. Ajtkhozhina, Alkaloid homoharringtonine inhibits polypeptide chain elongation on human ribosomes on the step of peptide bond formation, FEBS Lett, 257 (1989) 254-256.

[4] A. Quintas-Cardama, H. Kantarjian, J. Cortes, Homoharringtonine, omacetaxine mepesuccinate, and chronic myeloid leukemia circa 2009, Cancer, 115 (2009) 5382-5393.

[5] V. Gandhi, W. Plunkett, J.E. Cortes, Omacetaxine: a protein translation inhibitor for treatment of chronic myelogenous leukemia, Clinical cancer research : an official journal of the American Association for Cancer Research, 20 (2014) 1735-1740.

[6] A. Quintas-Cardama, J. Cortes, Homoharringtonine for the treatment of chronic myelogenous leukemia, Expert opinion on pharmacotherapy, 9 (2008) 1029-1037.

[7] S. O'Brien, H. Kantarjian, M. Keating, M. Beran, C. Koller, L.E. Robertson, J. Hester, M.B. Rios, M. Andreeff, M. Talpaz, Homoharringtonine therapy induces responses in patients with chronic myelogenous leukemia in late chronic phase, Blood, 86 (1995) 3322-3326. 
[8] D.L. Sudakin, Trichothecenes in the environment: relevance to human health, Toxicology letters, 143 (2003) 97-107.

[9] M.C. Arrieta, L. Bistritz, J.B. Meddings, Alterations in intestinal permeability, Gut, 55 (2006) 1512-1520.

[10] P. Pinton, J.P. Nougayrede, J.C. Del Rio, C. Moreno, D.E. Marin, L. Ferrier, A.P. Bracarense, M. Kolf-Clauw, I.P. Oswald, The food contaminant deoxynivalenol, decreases intestinal barrier permeability and reduces claudin expression, Toxicol Appl Pharmacol, 237 (2009) 41-48.

[11] J. McLaughlin, P.J. Padfield, J.P. Burt, C.A. O'Neill, Ochratoxin A increases permeability through tight junctions by removal of specific claudin isoforms, Am J Physiol Cell Physiol, 287 (2004) C1412-1417.

[12] J. McLaughlin, D. Lambert, P.J. Padfield, J.P. Burt, C.A. O'Neill, The mycotoxin patulin, modulates tight junctions in caco-2 cells, Toxicol In Vitro, 23 (2009) 83-89.

[13] P. Akbari, S. Braber, H. Gremmels, P.J. Koelink, K.A. Verheijden, J. Garssen, J. Fink-Gremmels, Deoxynivalenol: a trigger for intestinal integrity breakdown, FASEB J, 28 (2014) 2414-2429.

[14] B.M. Gumbiner, Breaking through the tight junction barrier, The Journal of cell biology, 123 (1993) 1631-1633.

[15] J.M. Anderson, C.M. Van Itallie, Tight junctions and the molecular basis for regulation of paracellular permeability, The American journal of physiology, 269 (1995) G467-475.

[16] M. Furuse, K. Fujita, T. Hiiragi, K. Fujimoto, S. Tsukita, Claudin-1 and -2: novel integral membrane proteins localizing at tight junctions with no sequence similarity to occludin, The Journal of cell biology, 141 (1998) 1539-1550. 
[17] M. Furuse, T. Hirase, M. Itoh, A. Nagafuchi, S. Yonemura, S. Tsukita, S. Tsukita, Occludin: a novel integral membrane protein localizing at tight junctions, The Journal of cell biology, 123 (1993) 1777-1788.

[18] I. Martin-Padura, S. Lostaglio, M. Schneemann, L. Williams, M. Romano, P. Fruscella, C. Panzeri, A. Stoppacciaro, L. Ruco, A. Villa, D. Simmons, E. Dejana, Junctional adhesion molecule, a novel member of the immunoglobulin superfamily that distributes at intercellular junctions and modulates monocyte transmigration, The Journal of cell biology, 142 (1998) 117-127.

[19] L. Gonzalez-Mariscal, A. Betanzos, A. Avila-Flores, MAGUK proteins: structure and role in the tight junction, Semin Cell Dev Biol, 11 (2000) 315-324.

[20] L.L. Mitic, J.M. Anderson, Molecular architecture of tight junctions, Annu Rev Physiol, 60 (1998) 121-142.

[21] M. Furuse, S. Tsukita, Claudins in occluding junctions of humans and flies, Trends Cell Biol, 16 (2006) 181-188.

[22] J.V. De Walle, T. Sergent, N. Piront, O. Toussaint, Y.J. Schneider, Y. Larondelle, Deoxynivalenol affects in vitro intestinal epithelial cell barrier integrity through inhibition of protein synthesis, Toxicol Appl Pharmacol, 245 (2010) 291-298.

[23] Y. Ueno, The toxicology of mycotoxins, Crit Rev Toxicol, 14 (1985) 99-132.

[24] S. Maher, L. Feighery, D.J. Brayden, S. McClean, Melittin as an epithelial permeability enhancer I: investigation of its mechanism of action in Caco-2 monolayers, Pharm Res, 24 (2007) 1336-1345.

[25] R. Tang, A.M. Faussat, P. Majdak, C. Marzac, S. Dubrulle, Z. Marjanovic, O. Legrand, J.P. Marie, Semisynthetic homoharringtonine induces apoptosis 
via inhibition of protein synthesis and triggers rapid myeloid cell leukemia-1 down-regulation in myeloid leukemia cells, Mol Cancer Ther, 5 (2006) 723-731.

[26] J. Kuroda, Y. Kamitsuji, S. Kimura, E. Ashihara, E. Kawata, Y. Nakagawa, M. Takeuichi, Y. Murotani, A. Yokota, R. Tanaka, M. Andreeff, M. Taniwaki, T. Maekawa, Anti-myeloma effect of homoharringtonine with concomitant targeting of the myeloma-promoting molecules, Mcl-1, XIAP, and beta-catenin, Int J Hematol, 87 (2008) 507-515.

[27] L. Yinjun, J. Jie, X. Weilai, T. Xiangming, Homoharringtonine mediates myeloid cell apoptosis via upregulation of pro-apoptotic bax and inducing caspase-3-mediated cleavage of poly(ADP-ribose) polymerase (PARP), Am J Hematol, 76 (2004) 199-204.

[28] H. Jie, H. Donghua, X. Xingkui, G. Liang, W. Wenjun, H. Xiaoyan, C. Zhen, Homoharringtonine-induced apoptosis of MDS cell line MUTZ-1 cells is mediated by the endoplasmic reticulum stress pathway, Leuk Lymphoma, 48 (2007) 964-977.

[29] H. Tong, Y. Ren, F. Zhang, J. Jin, Homoharringtonine affects the JAK2-STAT5 signal pathway through alteration of protein tyrosine kinase phosphorylation in acute myeloid leukemia cells, Eur J Haematol, 81 (2008) 259-266.

[30] A.G. Markov, A. Veshnyakova, M. Fromm, M. Amasheh, S. Amasheh, Segmental expression of claudin proteins correlates with tight junction barrier properties in rat intestine, J Comp Physiol B, 180 (2010) 591-598. [31] N. Burgel, C. Bojarski, J. Mankertz, M. Zeitz, M. Fromm, J.D. Schulzke, Mechanisms of diarrhea in collagenous colitis, Gastroenterology, 123 (2002) 433-443. 
[32] S. Amasheh, M. Fromm, D. Gunzel, Claudins of intestine and nephron a correlation of molecular tight junction structure and barrier function, Acta Physiol (Oxf), 201 (2011) 133-140.

[33] M. Takehara, T. Nishimura, S. Mima, T. Hoshino, T. Mizushima, Effect of claudin expression on paracellular permeability, migration and invasion of colonic cancer cells, Biol Pharm Bull, 32 (2009) 825-831.

[34] S. Amasheh, T. Schmidt, M. Mahn, P. Florian, J. Mankertz, S. Tavalali, A.H. Gitter, J.D. Schulzke, M. Fromm, Contribution of claudin-5 to barrier properties in tight junctions of epithelial cells, Cell Tissue Res, 321 (2005) 89-96.

[35] R. Al-Sadi, K. Khatib, S. Guo, D. Ye, M. Youssef, T. Ma, Occludin regulates macromolecule flux across the intestinal epithelial tight junction barrier, Am J Physiol Gastrointest Liver Physiol, 300 (2011) G1054-1064.

[36] M.G. Laukoetter, P. Nava, W.Y. Lee, E.A. Severson, C.T. Capaldo, B.A. Babbin, I.R. Williams, M. Koval, E. Peatman, J.A. Campbell, T.S. Dermody, A. Nusrat, C.A. Parkos, JAM-A regulates permeability and inflammation in the intestine in vivo, J Exp Med, 204 (2007) 3067-3076.

[37] K. Umeda, T. Matsui, M. Nakayama, K. Furuse, H. Sasaki, M. Furuse, S. Tsukita, Establishment and characterization of cultured epithelial cells lacking expression of ZO-1, J Biol Chem, 279 (2004) 44785-44794.

[38] C.M. Van Itallie, A.S. Fanning, A. Bridges, J.M. Anderson, ZO-1 stabilizes the tight junction solute barrier through coupling to the perijunctional cytoskeleton, Mol Biol Cell, 20 (2009) 3930-3940.

[39] A.S. Fanning, C.M. Van Itallie, J.M. Anderson, Zonula occludens-1 and -2 regulate apical cell structure and the zonula adherens cytoskeleton in polarized epithelia, Mol Biol Cell, 23 (2012) 577-590. 
[40] X. Guo, J.N. Rao, L. Liu, T.T. Zou, D.J. Turner, B.L. Bass, J.Y. Wang, Regulation of adherens junctions and epithelial paracellular permeability: a novel function for polyamines, Am J Physiol Cell Physiol, 285 (2003) C1174-1187.

[41] P. Sheth, A. Seth, M. Thangavel, S. Basuroy, R.K. Rao, Epidermal growth factor prevents acetaldehyde-induced paracellular permeability in Caco-2 cell monolayer, Alcohol Clin Exp Res, 28 (2004) 797-804.

[42] R. Chen, L. Guo, Y. Chen, Y. Jiang, W.G. Wierda, W. Plunkett, Homoharringtonine reduced Mcl-1 expression and induced apoptosis in chronic lymphocytic leukemia, Blood, 117 (2011) 156-164.

[43] F. Robert, M. Carrier, S. Rawe, S. Chen, S. Lowe, J. Pelletier, Altering chemosensitivity by modulating translation elongation, PLoS One, 4 (2009) e5428.

[44] M.A. Deli, Potential use of tight junction modulators to reversibly open membranous barriers and improve drug delivery, Biochim Biophys Acta, 1788 (2009) 892-910. 


\section{Figure legends}

Fig. 1 Effect of HHT on TER in Caco-2 cell monolayers.

Caco- 2 cells $\left(6 \times 10^{4}\right.$ cells $)$ were seeded on transwell inserts and grown for 10-14 days. (a) Cells were treated with vehicle or 1,5 , or $10 \mu \mathrm{M}$ HHT on the apical and basolateral side of the insert. After 1, 3, 6, 12, 18, 24, or $48 \mathrm{~h}$, the TER values were monitored at the indicated time. Relative TER was calculated as the percent of the TER values relative to the values at $0 \mathrm{~h}$. The data are means \pm S.D. $(\mathrm{n}=3)$. (b) Vehicle or HHT $(5 \mu \mathrm{M})$ was added to the apical, basolateral, or apical + basolateral side, and Caco-2 cells were cultured for $24 \mathrm{~h}$. Then, the TER values were measured. The data are means \pm S.D. $(n=3)$. (c) Caco-2 cells were treated with vehicle or $0.1,1$, or $10 \mu \mathrm{M}$ HHT for $24 \mathrm{~h}$, followed by measurement of LDH release; $0.2 \%$ Tween 20 served as a positive control. LDH release was calculated as a percentage of the LDH release by the vehicle-treated cells. The data are means \pm S.D. $(\mathrm{n}=3)$. (d) Caco-2 cells were treated with vehicle or 1,5 , or $10 \mu \mathrm{M}$ HHT (apical and basolateral exposure) for $24 \mathrm{~h}$, then the media were replaced with fresh medium. The cells were cultured for an additional $48 \mathrm{~h}$. TER values were monitored every $24 \mathrm{~h}$. Relative TER was calculated as the percent of the TER values relative to the values at $0 \mathrm{~h}$. The data are means \pm S.D. $(\mathrm{n}=3)$.

Fig. 2 Effect of HHT on paracellular flux in Caco-2 cell monolayers.

Caco-2 cells were grown and differentiated on transwell inserts. The cells were then treated with vehicle or 1,5 , or $10 \mu \mathrm{M} \mathrm{HHT}$ on the apical and basolateral sides of the insert for $24 \mathrm{~h}$. Then, the translocation of FITC-dextrans with a molecular weight of $4 \mathrm{kDa}$ (a) and $40 \mathrm{kDa}$ (b) from the apical to the basolateral chamber was performed, as described in the Materials and Methods section. The data are means \pm S.D. $(n=3)$.

Fig. 3 Effect of HHT on the expression of cell adhesion molecules. 
Caco- 2 cells $\left(7.5 \times 10^{5}\right.$ cells $)$ were seeded on transwell inserts and cultured for 10-14 days. (a) The cells were then treated with 0,1 , or $5 \mu \mathrm{M}$ HHT (a) or 0 or $5 \mu \mathrm{M}$ HHT (b) on the apical and basolateral sides of the insert for $24 \mathrm{~h}$. The cell lysates were collected and subjected to immunoblotting analysis for claudin (CL)-1, $-2,-3,-4,-5$, and -7 , occludin, JAM-A, ZO-1, ZO-2, and E-cadherin (a), and to qRT-PCR analysis for Claudin-1, -2, -3, $-4,-5$, and -7 (b); $\beta$-actin (a) served as a loading control.

Fig. 4 Effect of HHT on the cellular localization of cell adhesion molecules.

Caco- 2 cells $\left(1.5 \times 10^{5}\right.$ cells $)$ were seeded on transwell inserts and cultured for 10-14 days. The cells were then treated with vehicle or $5 \mu \mathrm{M}$ HHT on the apical and basolateral sides of the insert for $24 \mathrm{~h}$, followed by fixation and staining with anti-Claudin-1, -4 , occludin, ZO-1, and E-cadherin antibody, as described in the Materials and methods section. Scale bar $=10 \mu \mathrm{m}$.

Fig. 5 Time-course changes in the expression and cellular localization of claudin isoforms after HHT treatment.

Caco-2 cells were grown and differentiated on Transwell inserts. The cells were then treated with $5 \mu \mathrm{M}$ HHT on the apical and basolateral sides of the insert. Cell lysates were collected (a and c) or the cells were fixed (e) after $0,12,18$, or $24 \mathrm{~h}$ of HHT treatment, or after being cultured for an additional 24 or $48 \mathrm{~h}$ in fresh medium that lacked HHT. These samples were then subjected to immunoblotting analysis for claudin-1, $-3,-4,-5,-7$, or $\beta$-actin (a), and claudin-3, $-5,-7$, or $\beta$-actin (c), and to immunofluorescence staining analysis for claudin-1 and -4 (e). Expression of claudin-1, -3, -4, -5, and -7 proteins (a) and claudin-3, -5 , and -7 proteins (c) were estimated by densitometry after normalization with $\beta$-actin ( $b$ and $d$ ). Relative protein density was calculated as the ratio of the protein density to the density at $0 \mathrm{~h}$. The data presented are means \pm 1 S.D. $(n=3)$. Scale bar $=10$ 
$\mu \mathrm{m}$. 
Figure 1

b

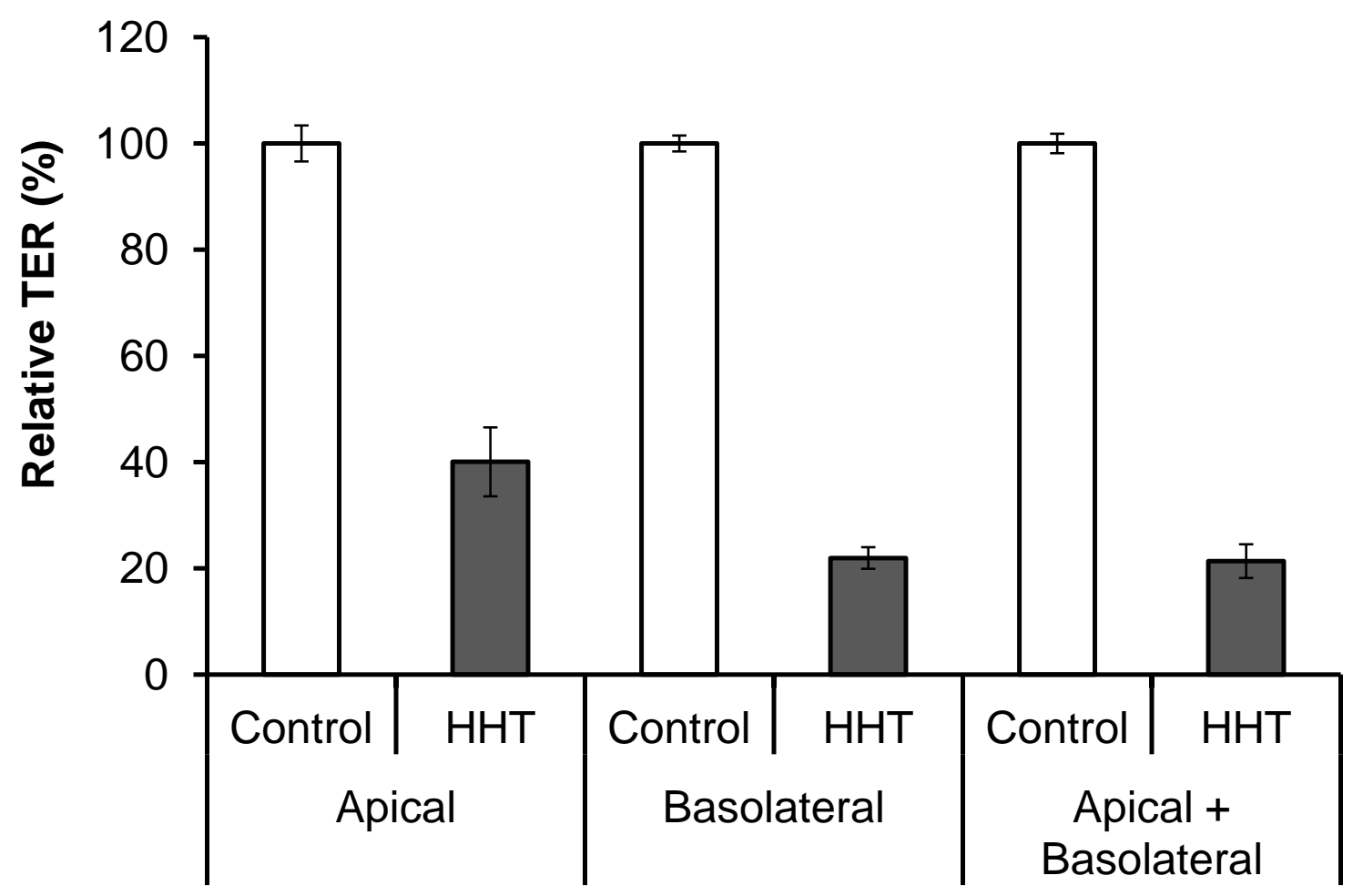

C

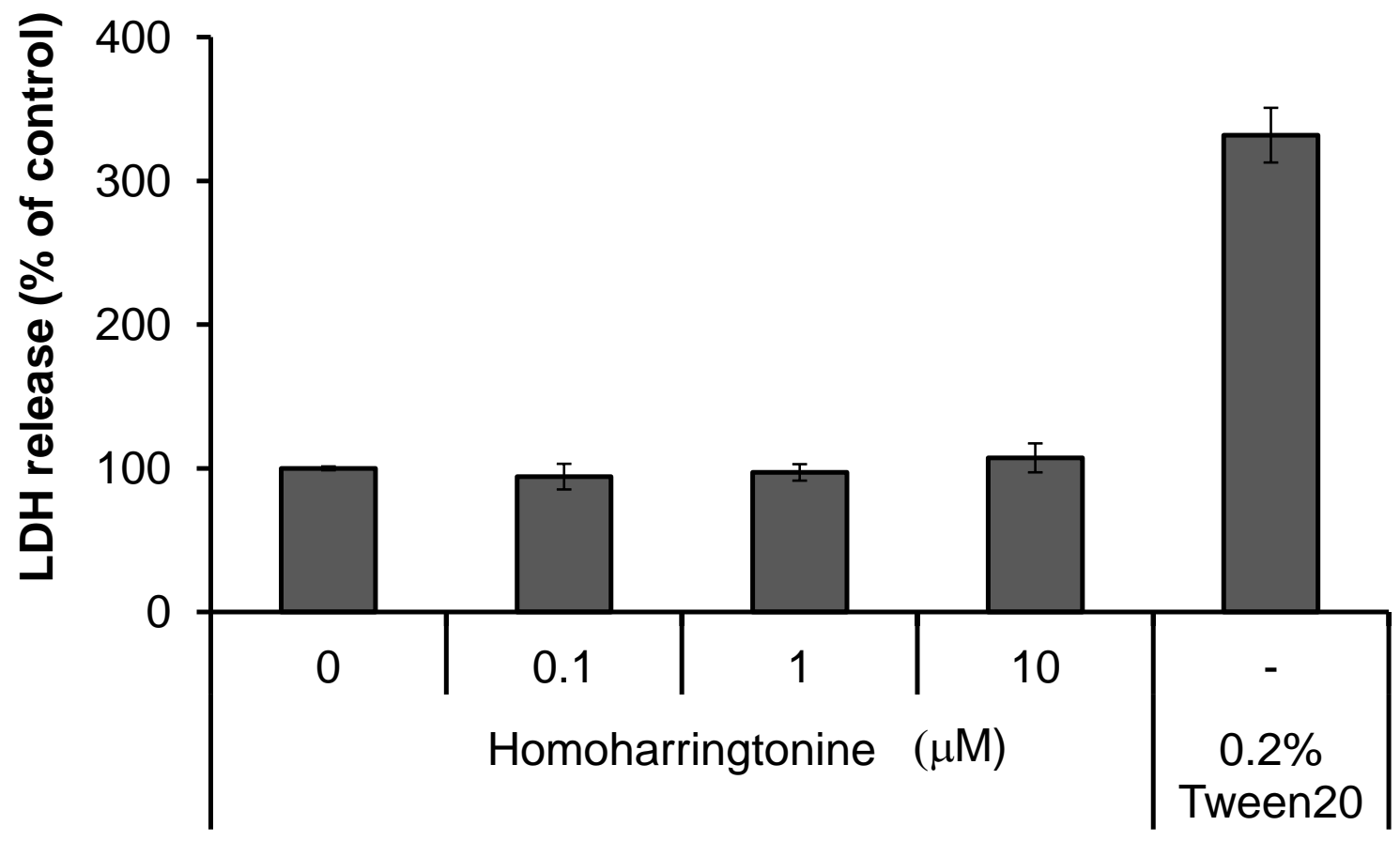


Figure 1

d

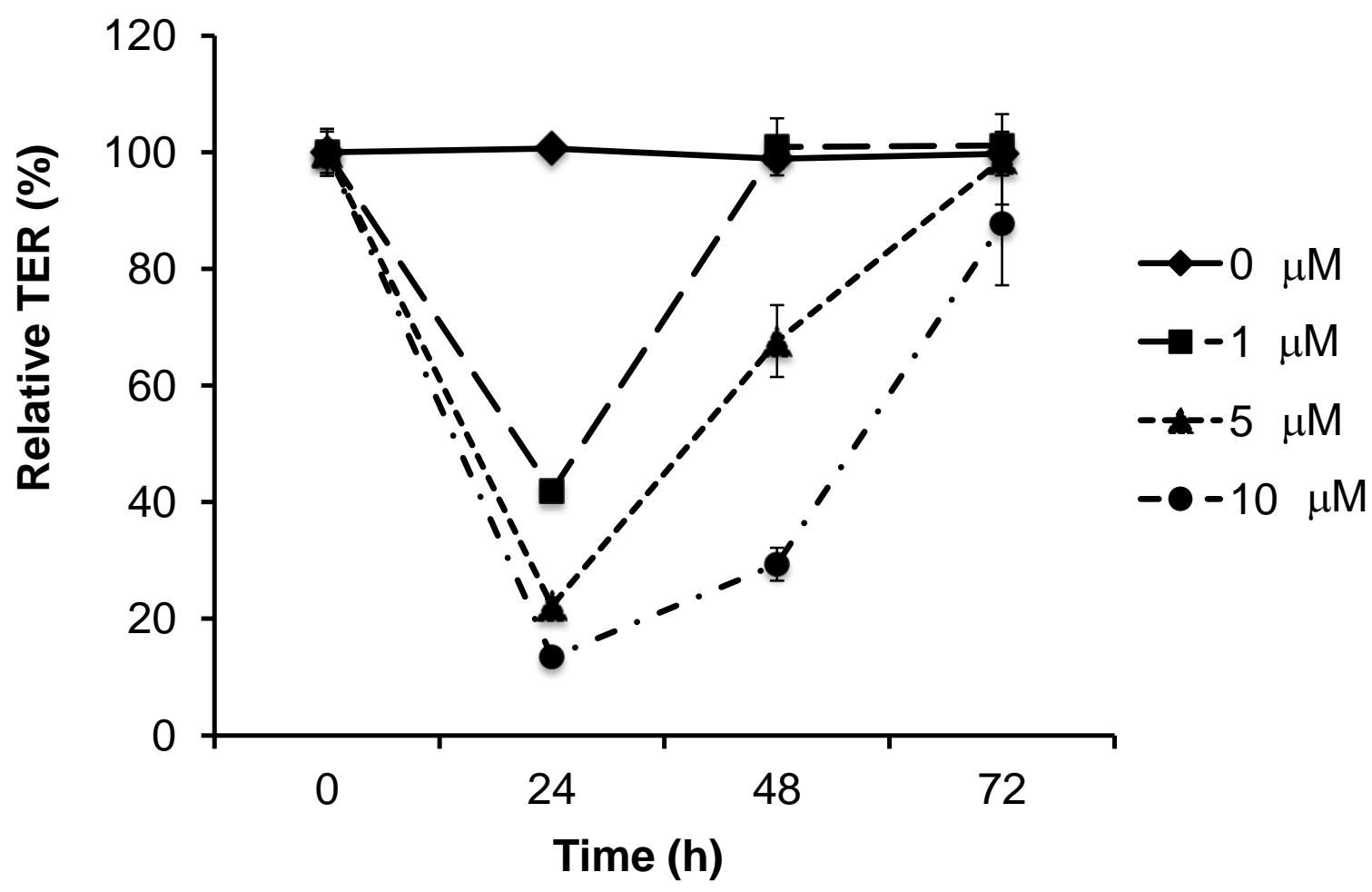


Figure 2

a

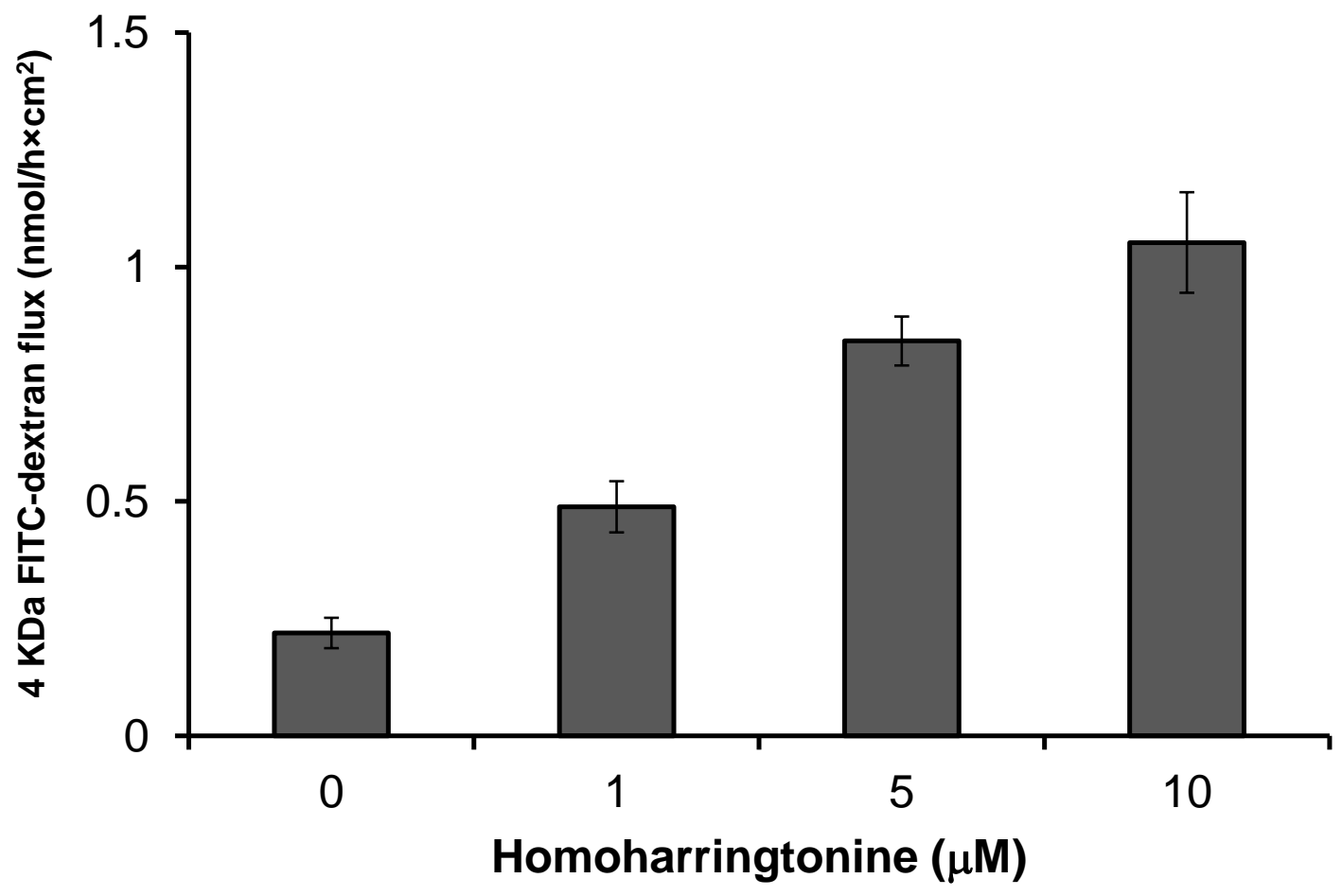

b

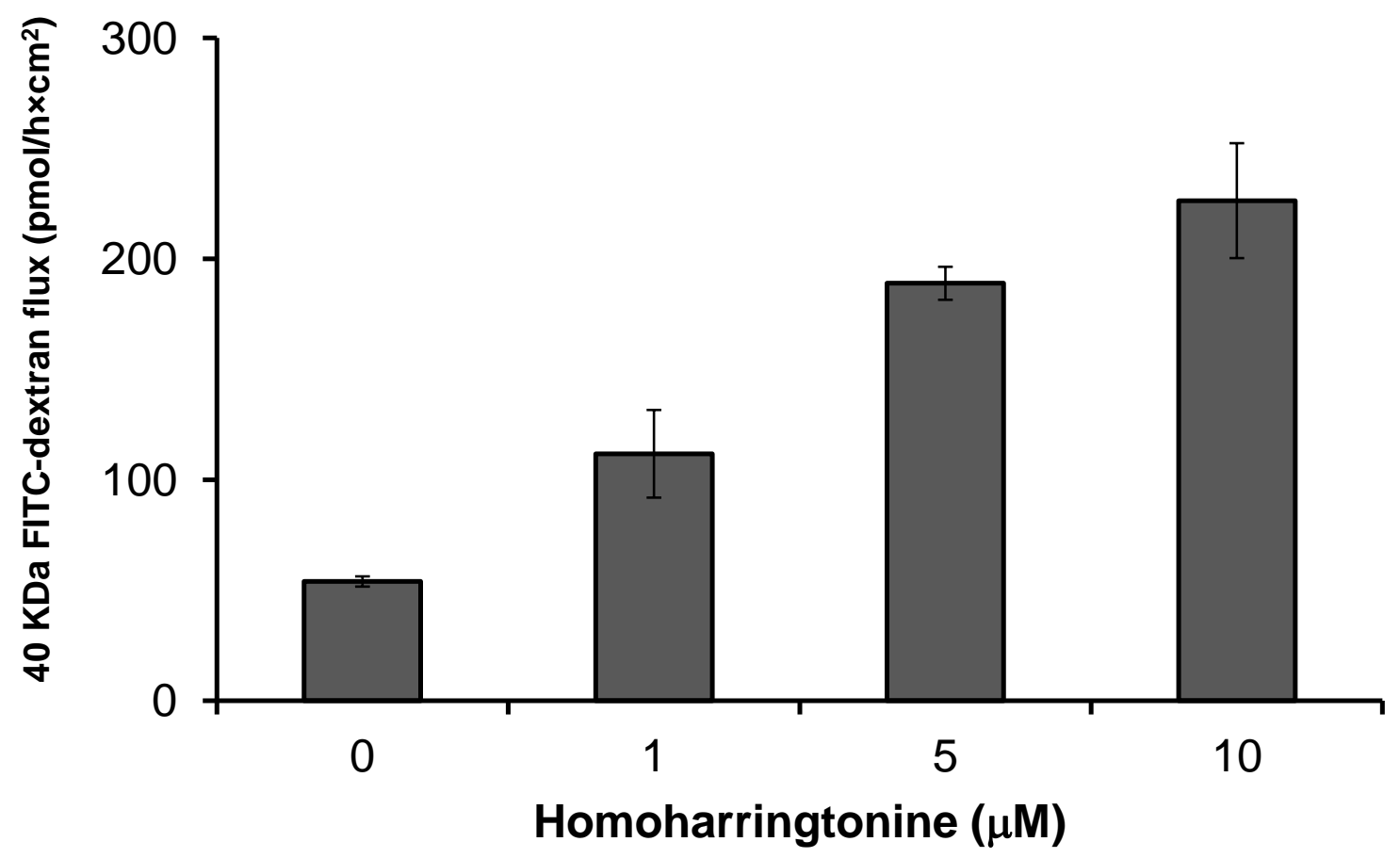


Figure 3

a

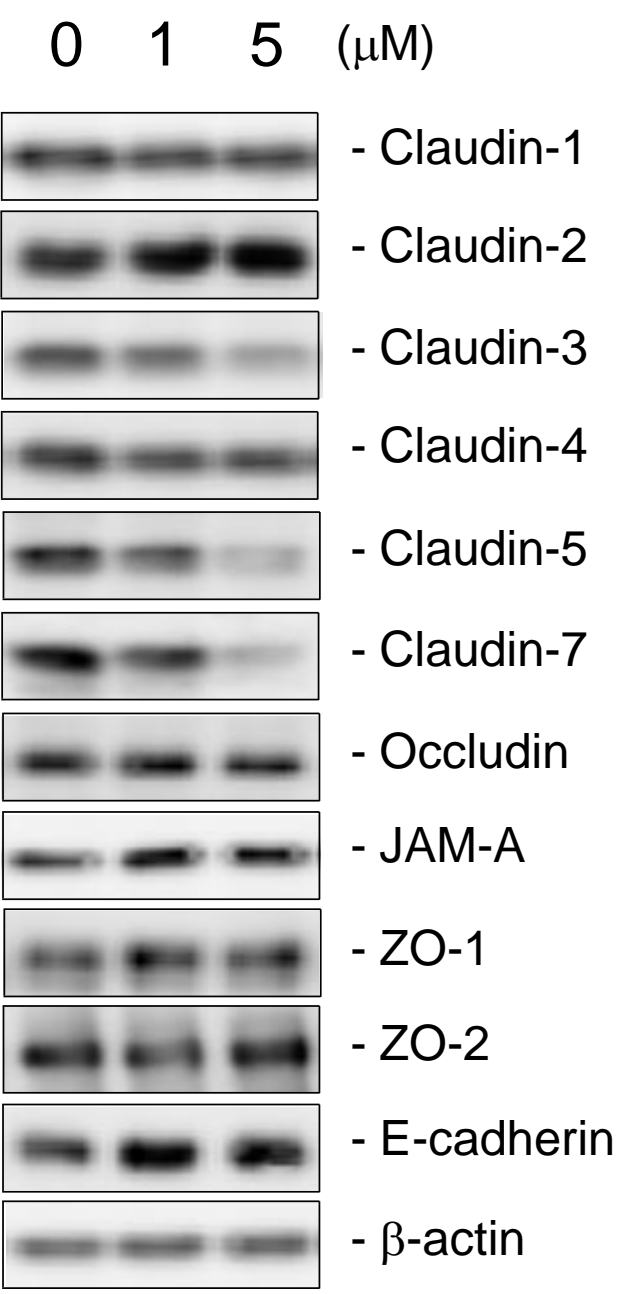


Figure 3

b

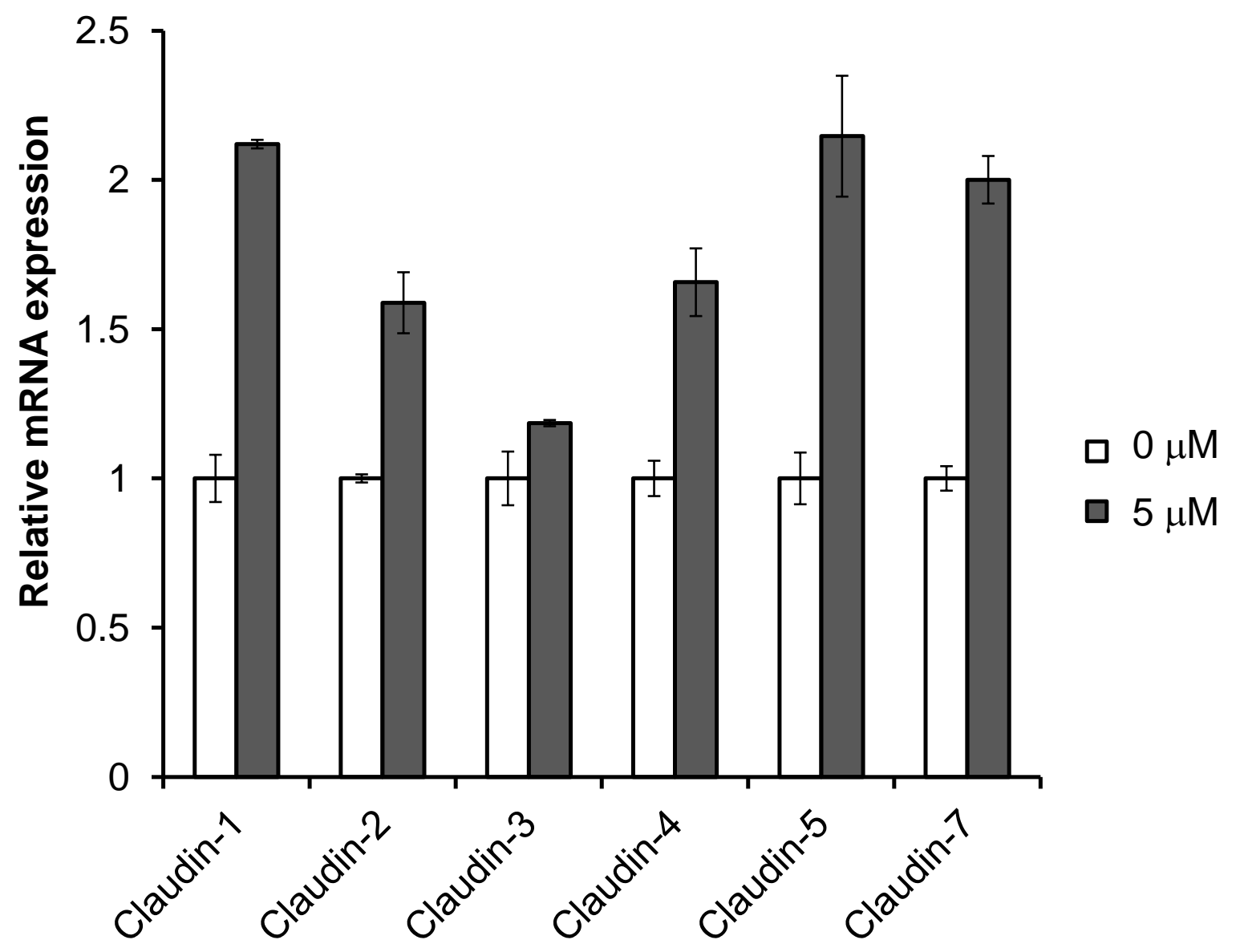


Figure 4

Control

Claudin-1

Claudin-4

ZO-1

Occludin

\section{E-cadherin}

HHT
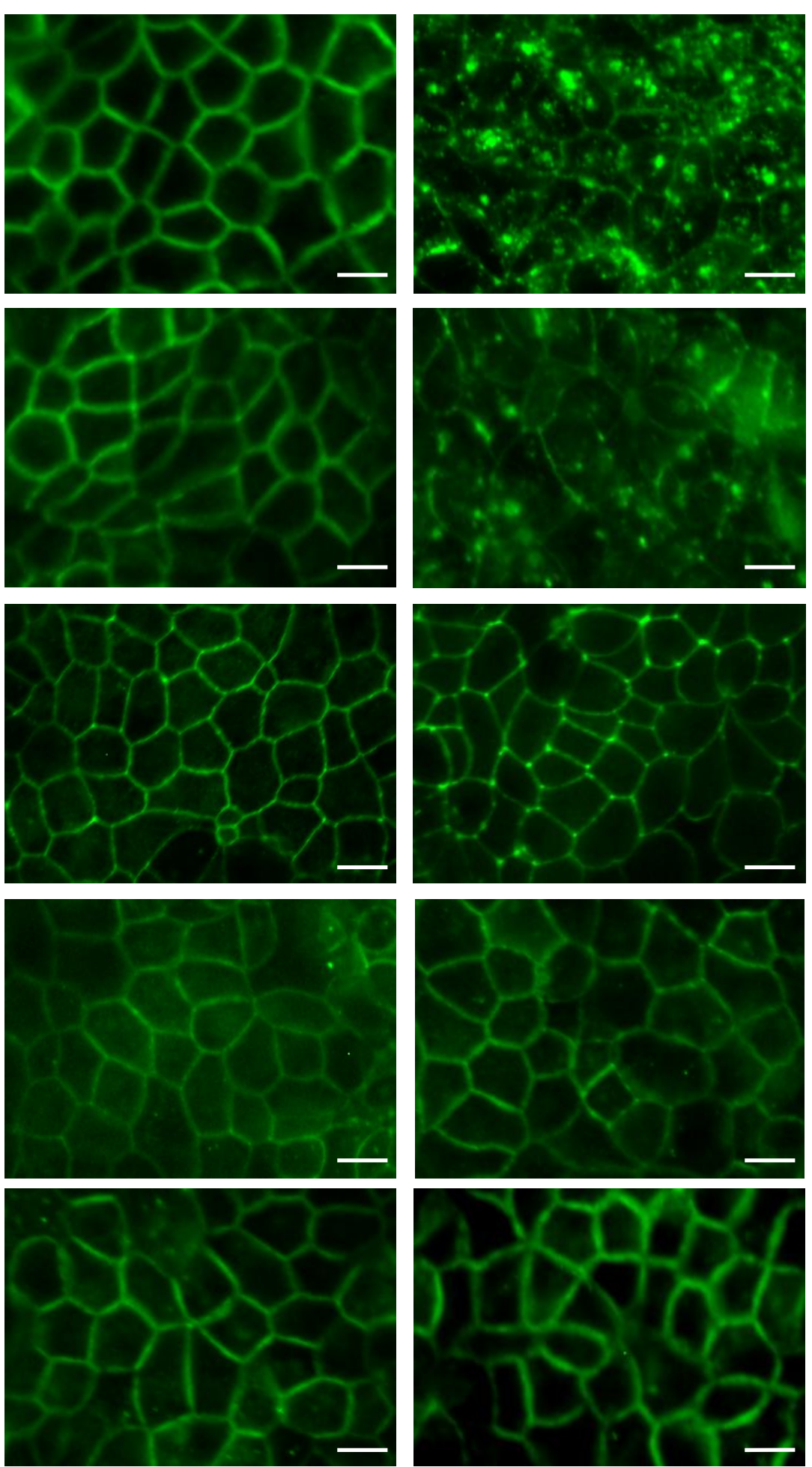
Figure 5

a

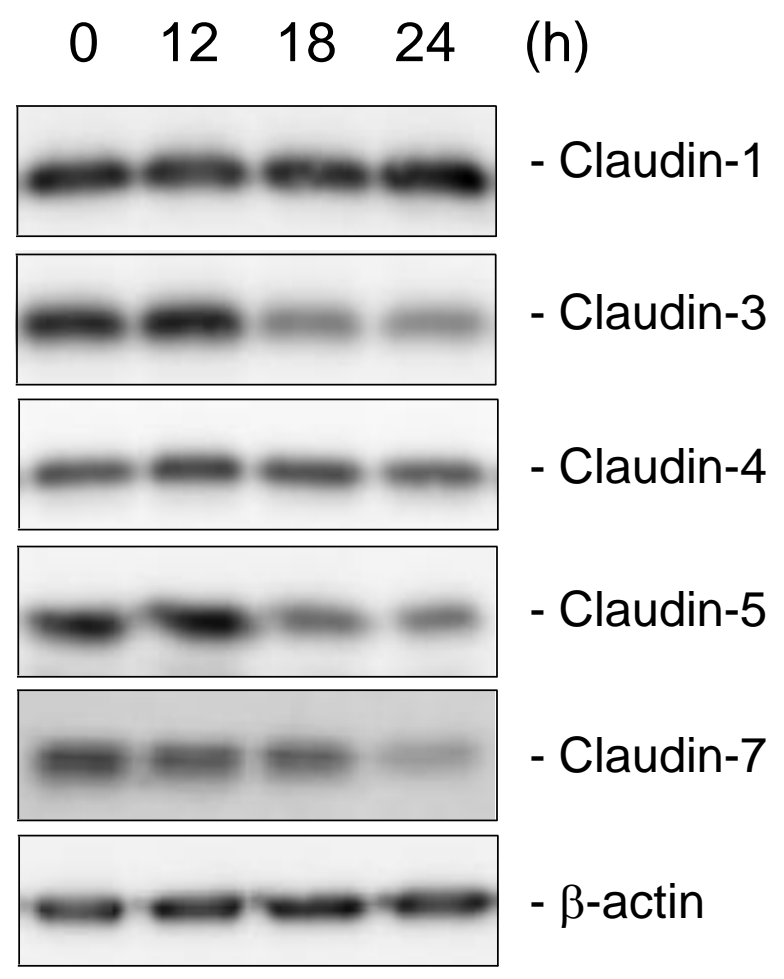

b

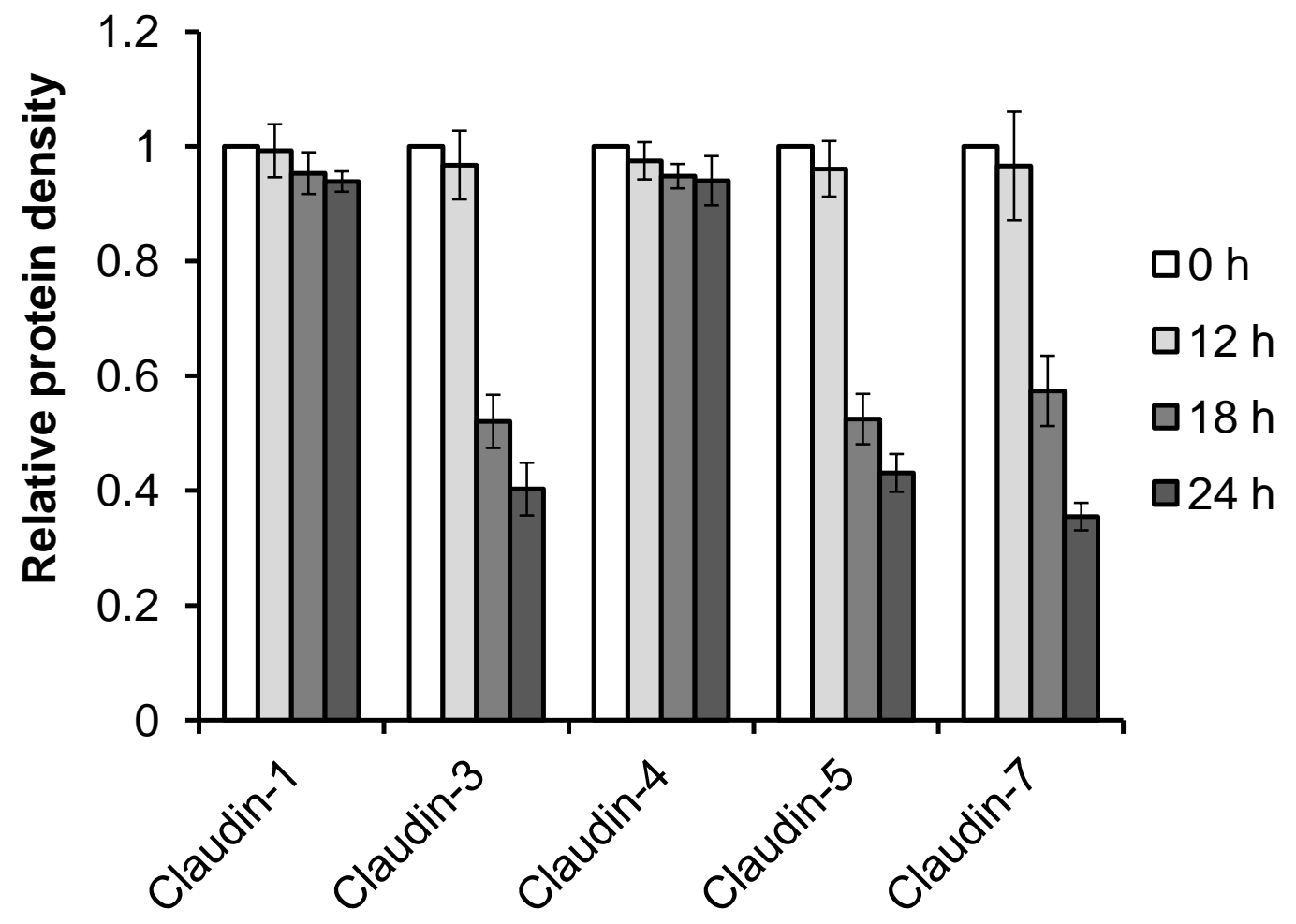


Figure 5

C

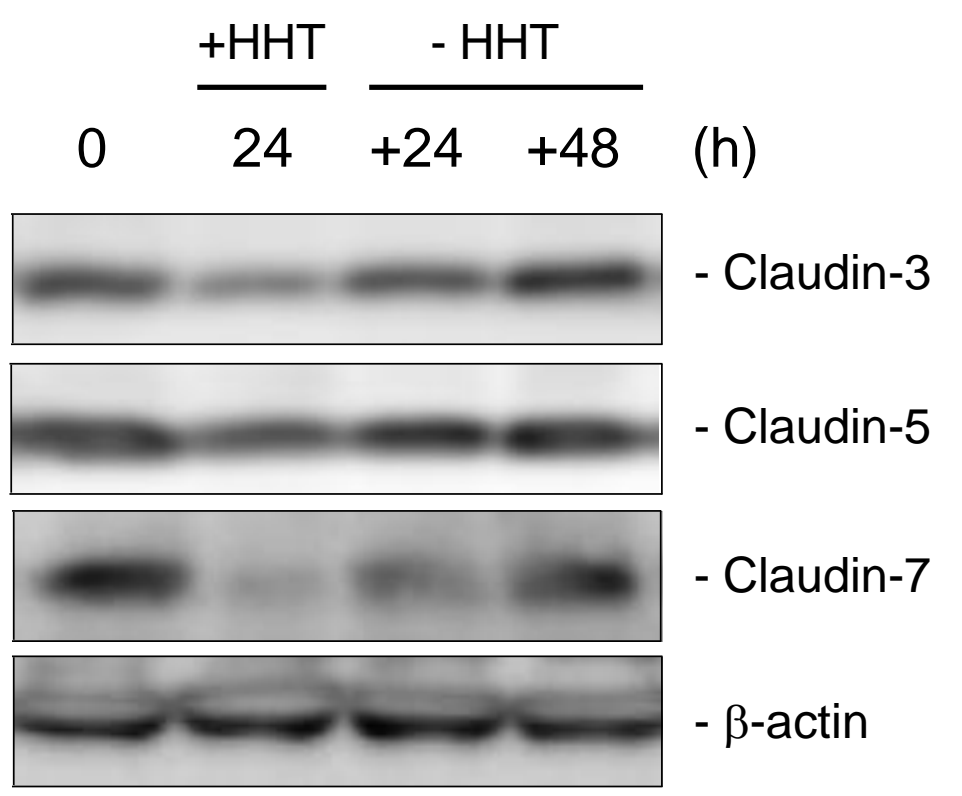

d

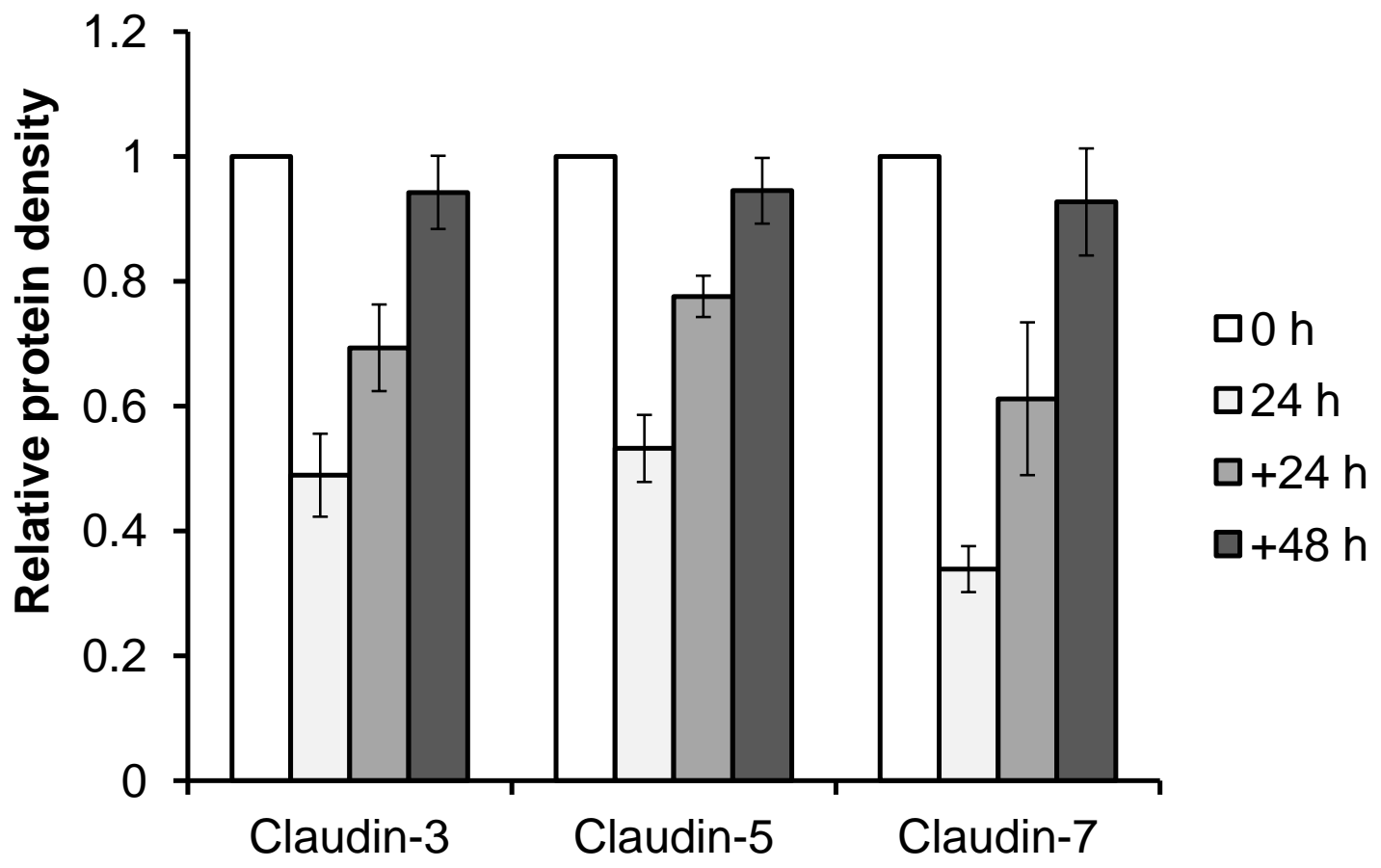


Figure 5

e

Claudin-1

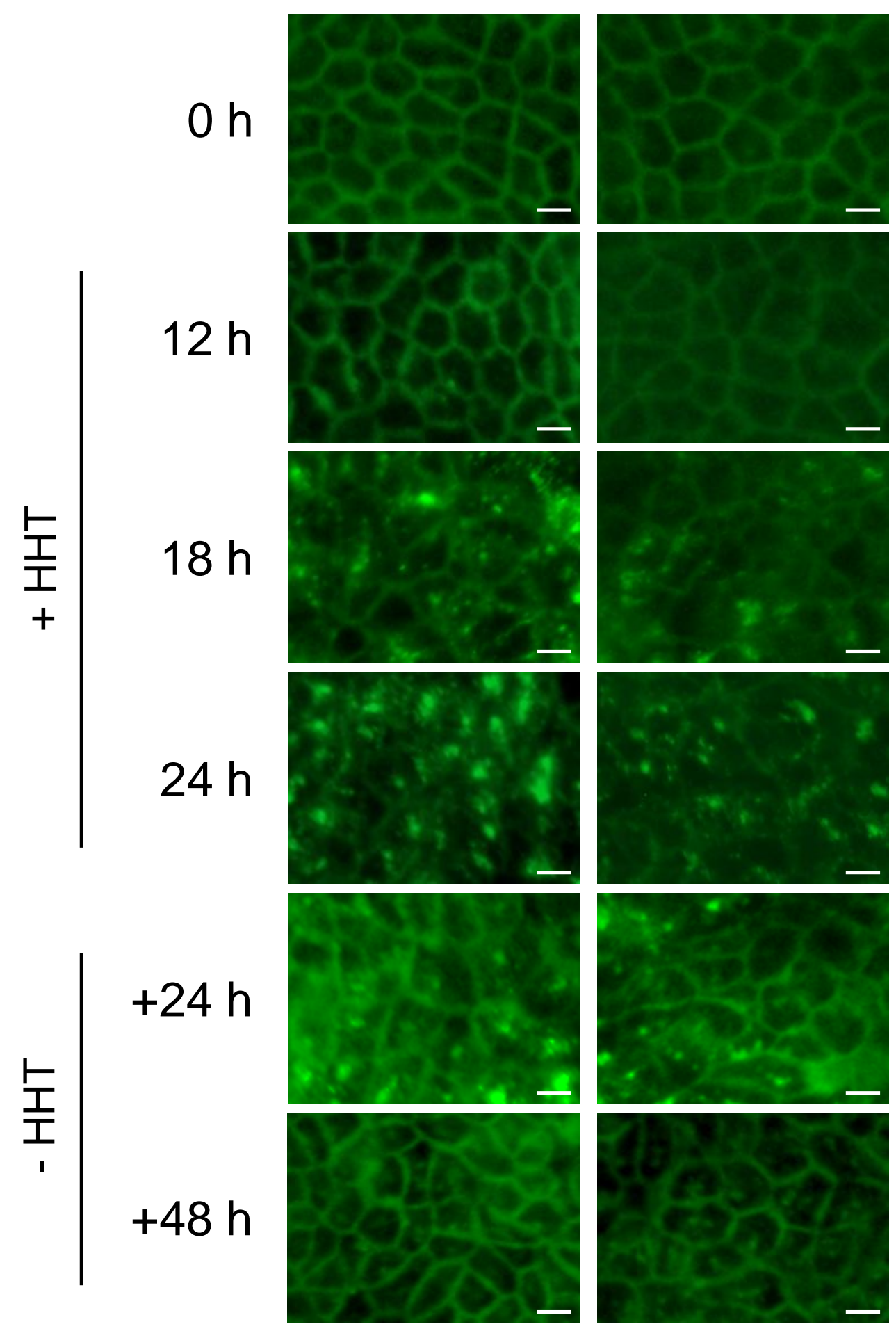




\section{Homoharringtonine (HHT)}

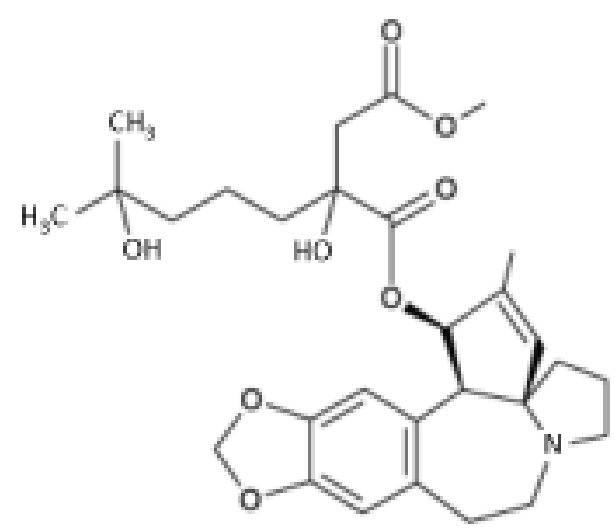

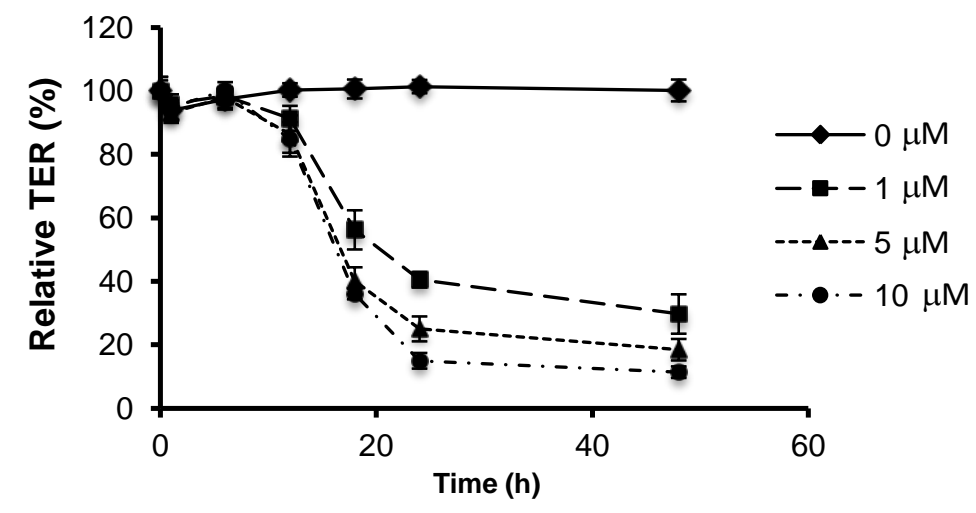

HHT decreases the protein level of the claudin isoforms.

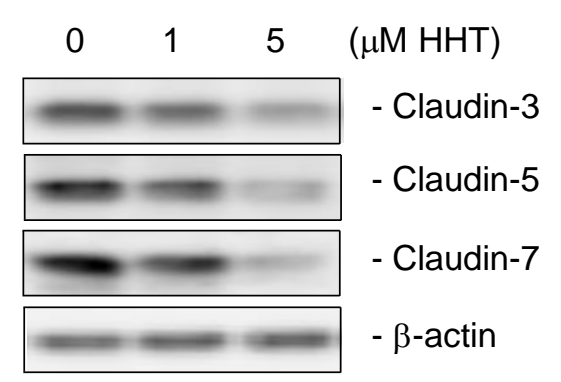

HHT disturbs the cellular localization of the claudin isoforms.

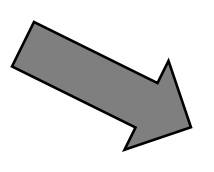

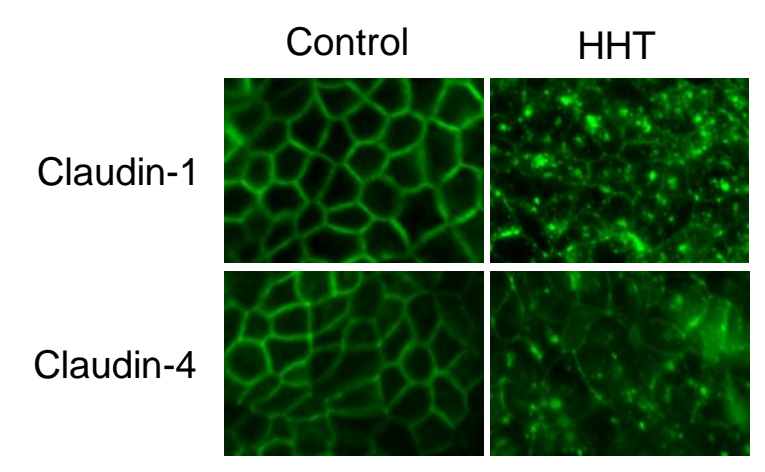

